\title{
Influences on the diet quality of pre-school children: importance of maternal psychological characteristics
}

\author{
Megan Jarman ${ }^{1,2, *}$, Hazel M Inskip ${ }^{1}$, Georgia $\operatorname{Ntani}^{1}$, Cyrus Cooper ${ }^{1,2,3}$, Janis Baird ${ }^{1}$, \\ Sian M Robinson ${ }^{1}$ and Mary E Barker ${ }^{1}$ \\ ${ }^{1}$ MRC Lifecourse Epidemiology Unit, University of Southampton, Southampton General Hospital, Southampton SO16 \\ 6YD, UK: ${ }^{2}$ NIHR Nutrition Biomedical Research Centre, University of Southampton and University Hospital \\ Southampton NHS Foundation Trust, Southampton, UK: ${ }^{3}$ NIHR Musculoskeletal Biomedical Research Unit, University \\ of Oxford, Oxford, UK
}

Submitted 24 February 2014: Final revision received 19 September 2014: Accepted 5 October 2014: First published online 20 November 2014

\begin{abstract}
Objective: To test the hypothesis that maternal psychological profiles relate to children's quality of diet.

Design: Cross-sectional study. Mothers provided information on their healthrelated psychological factors and aspects of their child's mealtime environment. Children's diet quality was assessed using an FFQ from which weekly intakes of foods and a diet $Z$-score were calculated. A high score described children with a better quality diet. Cluster analysis was performed to assess grouping of mothers based on psychological factors. Mealtime characteristics, describing how often children ate while sitting at a table or in front of the television, their frequency of takeaway food consumption, maternal covert control and food security, and children's quality of diet were examined, according to mothers' cluster membership.

Subjects: Mother-child pairs ( $n$ 324) in the Southampton Initiative for Health. Children were aged 2-5 years.

Setting: Hampshire, UK.

Results: Two main clusters were identified. Mothers in cluster 1 had significantly higher scores for all psychological factors than mothers in cluster 2 (all $P<0 \cdot 001$ ). Clusters were termed 'more resilient' and 'less resilient', respectively. Children of mothers in the less resilient cluster ate meals sitting at a table less often $(P=0.03)$ and watched more television $(P=0 \cdot 01)$. These children had significantly poorerquality diets $(\beta=-0.61,95 \% \mathrm{CI}-0.82,-0 \cdot 40, P \leq 0 \cdot 001)$. This association was attenuated, but remained significant after controlling for confounding factors that included maternal education and home/mealtime characteristics $(P=0 \cdot 006)$. Conclusions: The study suggests that mothers should be offered psychological support as part of interventions to improve children's quality of diet.
\end{abstract}

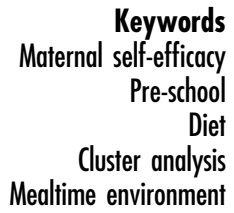

Population studies from around the world have shown that there are inequalities in the quality of young children's diets, with children from more disadvantaged families tending to have the poorest-quality diets ${ }^{(1-4)}$. Establishing a good-quality diet in early life is important for optimal growth and development as well as for long-term health. A good-quality diet is typically characterised by high intakes of unprocessed, micronutrient-dense foods (e.g. fruit, vegetables and whole-grains), and conversely a poorquality diet is typically characterised by high intakes of highly processed foods and foods high in fat, salt or sugar (e.g. potato chips, white bread and soft drinks) ${ }^{(1)}$.

To intervene to influence the quality of young children's diets requires an understanding of the determinants of food choice at this age. The association between children's quality of diet and socio-economic factors is well established ${ }^{(1-4)}$, but in addition influences within the child's immediate environment and a number of maternal, child, mealtime and home environmental characteristics appear to be important. The home food environment has been studied extensively with no consistent definitions of the concept. Rosencranz and Dzewaltowski addressed this by developing a comprehensive framework of the factors included in the home food environment ${ }^{(5)}$. They showed that home food environment is a global term which could include many factors. Our study focused on the child's physical mealtime environment, which Rosencranz and Dzewaltowski describe as 'family eating 
patterns'. This includes whether children are sat at a table or in front of the television to eat their meals and how often meals consist of takeaway foods. In addition, household food security is an important factor in the model of the home food environment. All of these factors have been shown to be associated with pre-school children's quality of diet. For example, children who consume meals while sitting at the table and with other family members present are more likely to have better-quality diets ${ }^{(6,7)}$, whereas children who eat their meals in front of the television and who live in a food-insecure household have been shown to have diets of poorer quality ${ }^{(8,9)}$. Moreover, maternal factors such as educational attainment ${ }^{(2)}$ and the way in which a mother exercises control over her child's diet $^{(10)}$ have also been identified as influences on children's diet quality. These factors are often interrelated, however, and there have been some studies that have considered multiple characteristics of the mother and home/mealtime environment and how, in combination, they influence the quality of young children's diets.

One such study assessed how aspects of the home mealtime environment and parental feeding practices influenced pre-school children's dietary patterns. It reported that children who were allowed to consume meals in front of the television, did not eat in the company of their parents and were in households which purchased more takeaway foods were more likely to have a poorer quality of diet. In addition, children whose parents used food as a reward and who did not restrict access to foods were also likely to have poorer-quality diets ${ }^{(11)}$. A more recent, comprehensive study that considered the interplay between some parental and home environmental factors suggested that parents cluster into groups according to aspects of their diet-related parenting practices (e.g. whether parents have rules about, or model, fruit, snack and sugar-sweetened beverage intake) and their food environment such as availability, accessibility and visibility of more and less healthy foods ${ }^{(12)}$. These clusters were associated with children's fruit, snack and sugar-sweetened beverage intake. For example, parents in the 'high visibility and accessibility of unhealthy foods' cluster were likely to have children who consumed more unhealthy and fewer healthier foods, while the reverse was seen in children whose parents were in the low availability of unhealthy foods' cluster ${ }^{(12)}$. That study implied that some maternal characteristics, the home and mealtime environments and parental feeding practices may work in combination to determine children's quality of diet.

To date there has been little consideration of the role of individual psychological characteristics of parents and how they shape the home food environment of young children or their quality of diet. Maternal psychological factors are known to be important determinants of the food choices a woman makes for herself. Bandura's social cognitive theory of the socio-environment and personal determinants of health behaviours holds self-efficacy as a central construct. Self-efficacy describes an individual's belief in his/her ability to carry out a behaviour and has been shown to be an important predictor of women's quality of diet ${ }^{(13)}$. In addition, factors such as perceived control over life, food involvement (which indicates the importance someone places on food) and well-being ${ }^{(14,15)}$ have been shown to be associated with quality of diet in women, which in turn is known to be an important influence over the way that they feed their children ${ }^{(16-18)}$. These psychological factors are also known to be highly correlated with one another. Perceptions of control in some senses overlap with self-efficacy ${ }^{(19)}$ and self-efficacy underlies a sense of well-being ${ }^{(20)}$. A small number of studies have considered individual maternal psychological factors in relation to child diet. One such study has shown a direct association between mother's level of food involvement and child's quality of diet, demonstrating that mothers with lower levels of food involvement have children who consume fewer fruits and vegetables ${ }^{(21)}$. Another study reported that mothers with higher levels of negative affect (lower well-being) tended to feed their children a diet higher in low-micronutrient, energy-dense foods such as chips, cakes and sugar-sweetened soft drinks ${ }^{(22)}$.

To date, however, there has been little exploration of the interrelationship between maternal psychological characteristics, young children's mealtime environment and their combined impact on young children's quality of diet. Based on the known relationships between maternal psychological characteristics and food choice in women, it is hypothesised that mothers who feel more in control of life and have higher levels of self-efficacy, well-being and food involvement will manage their children's mealtime environments more favourably and have children with better quality of diet.

\section{Methods}

\section{Participants}

Participants were a sub-sample of women enrolled in a larger study, the Southampton Initiative for Health $(\mathrm{SIH})^{(23)}$, who had a child aged between 2 and 5 years old. The SIH was a community-based intervention study that aimed to improve the diets and lifestyles of women of childbearing age. The present sub-study aimed to examine the relationship between nutrition behaviours in mothers and their young children.

\section{Procedure}

Between January and July 2009, 1022 women attending Sure Start Children's Centres in Southampton, Gosport and Havant, towns on the south coast of the UK, were recruited to the SIH study, representing $96 \%$ of those who were approached. Women were asked if they would be willing to provide information about their own diet and 
health-related behaviours, and 973 women who completed the baseline study agreed to be contacted again. Details of the procedures used in the SIH have been published elsewhere ${ }^{(23)}$. Of these 973 women, 572 (59\%) had a child between the ages of 2 and 5 years and were contacted again via telephone between December 2009 and May 2010 and invited to take part in the sub-study. Over $60 \%$ ( $n$ 348) of mothers agreed to take part and completed the sub-study. If the mother had two eligible children, she was asked about the younger child. Information was collected during telephone interviews by trained fieldworkers who adhered to a strict study protocol. At the beginning of the telephone call, the interviewer read out a participant information sheet and answered any questions that arose. Verbal consent to take part in the study was obtained over the telephone. The study was conducted according to the guidelines laid down in the Declaration of Helsinki and all procedures involving human participants were approved by the University of Southampton School of Medicine ethics committee.

\section{Materials}

The validated scales included in the questionnaires to assess general and specific self-efficacy, perceived control, food involvement, well-being, overt and covert control, food security and screen time are detailed in Table 1.

\section{Development of the $F F Q$}

A short FFQ was developed for the current study based on data collected from 1640 children aged 3 years who were part of the Southampton Women's Survey (SWS), a birth cohort study. Diets of children in the SWS were assessed using an interviewer administered eighty-item $\mathrm{FFQ}^{(1)}$. In a principal component analysis, the primary dietary pattern among these children was characterised by frequent consumption of fruit, vegetables and wholemeal bread and infrequent consumption of potato chips, crisps, sweets and soft drinks. This pattern was labelled 'prudent'. A prudent dietary pattern score was calculated for each child using the component coefficients and reported frequencies of consumption. Prudent diet scores indicate compliance with the prudent pattern and were used as an indicator of the children's diet quality ${ }^{(1)}$. We have previously shown that a short FFQ that includes the twenty foods that characterise the prudent dietary pattern can be used to assess this dietary pattern in young women and that prudent pattern scores for short and long FFQ are highly correlated $^{(24)}$. Furthermore, comparable positive associations between prudent diet scores defined using the short and long FFQ were found with a blood biomarker (red cell folate). In the present study, the twenty foods that had the greatest influence on the prudent diet pattern at 3 years in the SWS were used to construct a short FFQ to assess diet quality in young children. To evaluate the ability of the short, twenty-item FFQ used in the present study to rank children according to their compliance with the prudent diet pattern, a pilot study was carried out in which the diets of forty-five pre-school children were assessed using both the long eighty-item FFQ and the shorter twenty-item FFQ. The assessments were separated by between 12 and 20 weeks. Prudent diet scores from the full and short FFQ were found to be highly correlated $(r=0 \cdot 68, P=<0 \cdot 001)$.

\section{Assessment of children's diet quality}

Children's quality of diet was assessed using the short FFQ administered to the mother, to report how often in the last three months her child had consumed twenty food and drink items. Responses were 'never', 'less than once per month', '1-3 times per month', 'between 1-7 times per week' or 'more than once per day'. If any food or drink items were consumed more than once per day then the number of times was recorded. A prudent diet score was calculated for each child by taking the sum of the coefficients from principal component analysis multiplied by the reported frequency of consumption for each of the twenty food items. Scores were standardised and expressed at $Z$-scores such that they have a mean of 0 and a standard deviation of 1 .

\section{Home and mealtime environment}

The mealtime environment was assessed using tools developed in previous studies. Mothers were asked how often in the last three months her child had: 'eaten an evening meal with the family?' and 'eaten meals whilst the television was on?'(6), 'eaten takeaway foods, including fish and chips?' ${ }^{, 25)}$ and 'eaten whilst sat at a table?'(9) The responses were 'never', 'less than once per month', 'once every two weeks', '1-2 times per week', '3-6 times per week', 'once per day' and 'more than once per day'. Responses were coded from 0 to 6 .

Information on mother's diet, educational attainment, employment, age, number of children and clothing size was also collected. A UK clothing size of 16 or smaller is associated with lower odds of developing cardiovascular risk factors such as hypertension or type 2 diabetes ${ }^{(26)}$.

\section{Statistical analysis}

Statistical analysis was carried out using the statistical software package Stata version 12. A Spearman rank correlation matrix was used to assess the relationships between the maternal psychological variables and children's quality of diet. Cluster analysis was performed on the psychological variables (general control, well-being, general self-efficacy, self-efficacy for healthy eating and food involvement) using Ward's linkage to generate initial clusters. The resulting dendrogram from this hierarchical procedure was used to determine the number of clusters. Following this $k$-means analysis based on squared Eucilidean distances was used as a further iterative process, as recommended by Milligan and Cooper ${ }^{(27)}$. Child's median weekly food consumption according to mother's cluster 
Table 1 Assessments used in the maternal and child questionnaires

\begin{tabular}{|c|c|c|c|c|}
\hline Measure & Authors & Example item & Scoring & Cronbach's $a^{*}$ \\
\hline General self-efficacy scale & $\begin{array}{l}\text { Adapted from Schwarzer and } \\
\text { Jerusalem }\end{array}$ & $\begin{array}{l}\text { 'If I am in trouble I can usually find a } \\
\text { way out' }\end{array}$ & $\begin{array}{l}\text { Five items assessed on a 4-point scale of 'strongly agree' - } \\
\text { 'strongly disagree'. Score ranges from } 5 \text { to } 25 \text { with a higher } \\
\text { score indicating more self-efficacy }\end{array}$ & $0 \cdot 71$ \\
\hline $\begin{array}{l}\text { Self-efficacy for healthy } \\
\text { eating scale }\end{array}$ & $\begin{array}{l}\text { Adapted from Schwarzer and } \\
\text { Renner }{ }^{(40)}\end{array}$ & $\begin{array}{l}\text { 'I know I could stick to eating healthy } \\
\text { foods even if I don't receive much } \\
\text { support from others' }\end{array}$ & $\begin{array}{l}\text { Five items assessed on a 4-point scale of 'strongly agree' - } \\
\text { 'strongly disagree'. Score ranges from } 5 \text { to } 25 \text { with a higher } \\
\text { score indicating more self-efficacy for eating a healthy diet }\end{array}$ & 0.87 \\
\hline $\begin{array}{l}\text { Perceived control over life } \\
\text { scale }\end{array}$ & Bobak et al. ${ }^{(41)}$ & $\begin{array}{l}\text { 'I feel that what happens in my life is } \\
\text { often determined by factors beyond } \\
\text { my control' }\end{array}$ & $\begin{array}{l}\text { Nine items assessed on a 4-point scale of 'strongly agree' - } \\
\text { 'strongly disagree'. Score ranges from } 9 \text { to } 36 \text { with a higher } \\
\text { score indicating more perceived control }\end{array}$ & 0.69 \\
\hline Food involvement scale & Bell and Marshall ${ }^{(42)}$ & $\begin{array}{l}\text { 'Compared to other decisions in my } \\
\text { life my food choices are not very } \\
\text { important' }\end{array}$ & $\begin{array}{l}\text { Twelve items assessed on a 5-point scale of 'strongly agree' - } \\
\text { 'strongly disagree'. Score ranges from } 12 \text { to } 60 \text { with a higher } \\
\text { score indicating more food involvement }\end{array}$ & 0.63 \\
\hline Well-being scale & $\mathrm{WHO}^{(43)}$ & $\begin{array}{l}\text { 'Over the last two weeks I have felt } \\
\text { cheerful and in good spirits' }\end{array}$ & $\begin{array}{l}\text { Five items assessed on a 5-point scale of 'at no time' - 'all of } \\
\text { the time'. Score ranges from } 5 \text { to } 25 \text { with a higher score } \\
\text { indicating more well-being }\end{array}$ & 0.82 \\
\hline Overt control scale & Ogden et al. ${ }^{(44)}$ & $\begin{array}{l}\text { 'How often are you firm about what } \\
\text { your child should eat?' }\end{array}$ & $\begin{array}{l}\text { Five items assessed on a 5-point scale of 'never' - 'always'. } \\
\text { Score ranges from } 5 \text { to } 25 \text { with a higher score indicating } \\
\text { using more overt control }\end{array}$ & 0.59 \\
\hline Covert control scale & Ogden et al. ${ }^{(44)}$ & $\begin{array}{l}\text { 'How often do you avoid buying } \\
\text { sweets and crisps and bringing } \\
\text { them into the house?' }\end{array}$ & $\begin{array}{l}\text { Five items assessed on a } 5 \text {-point scale of 'never' - 'always'. } \\
\text { Score ranges from } 5 \text { to } 25 \text { with a higher score indicating } \\
\text { using more covert control }\end{array}$ & $0 \cdot 76$ \\
\hline Food security & $\begin{array}{l}\text { Blumberg et al. }{ }^{(45)} \text { adapted for } \\
\text { the UK population }\end{array}$ & $\begin{array}{l}\text { 'In the last } 12 \text { months did you ever } \\
\text { reduce the size or skip meals } \\
\text { because there wasn't enough } \\
\text { money for food?' }\end{array}$ & $\begin{array}{l}\text { Six items, scored by totalling affirmative responses. Score } \\
\text { ranges from } 0 \text { to } 6 \text {, with } \leq 2=\text { food secure, }>2 \text { and }<5=\text { food } \\
\text { insecure without hunger, } \geq 5=\text { food insecure with hunger }\end{array}$ & Not applicable \\
\hline Screen time & $\begin{array}{l}\text { Adapted to include computer } \\
\text { time from Miller et al. }{ }^{(35)}\end{array}$ & $\begin{array}{l}\text { 'Hour many hours on average does } \\
\text { your child spend watching } \\
\text { television per day?' }\end{array}$ & $\begin{array}{l}\text { Responses were '0', '<1', ' } 1-2 \text { ' etc. up to ' }>5 \text { ' } \mathrm{h} / \mathrm{d} \text {. Time spent } \\
\text { watching television/DVD and playing on a computer was } \\
\text { summed for each child to give total 'screen time' }\end{array}$ & Not applicable \\
\hline
\end{tabular}

${ }^{*}$ Cronbach's $a$ is an assessment of internal validity in scales; a score of above 0.6 is generally considered to represent good internal validity. 
membership was assessed using the median test for difference. Differences in characteristics according to cluster membership were assessed using $\chi^{2}$ statistics for categorical data and $t$ tests for parametric continuous variables. Univariate and multivariate linear regression models were used to assess the relationships between cluster membership and children's quality of diet.

\section{Results}

\section{Characteristics of mothers and children}

Complete data were available on 324 mothers and children. Table 2 describes the child, maternal and home/ mealtime characteristics of the 324 mother-child pairs. Due to small numbers some categories were collapsed in

Table 2 Characteristics of the 324 mother-child pairs studied, Southampton Initiative for Health, UK, December 2009-May 2010

\begin{tabular}{|c|c|c|}
\hline & Mean, median or $n$ & SD, \% or IQR \\
\hline \multicolumn{3}{|l|}{ Child characteristics } \\
\hline Age (years), mean and SD & 3.2 & 0.9 \\
\hline \multicolumn{3}{|l|}{ Gender, $n$ and $\%$} \\
\hline Male & 162 & 50 \\
\hline Female & 162 & 50 \\
\hline \multicolumn{3}{|l|}{ Number of siblings, $n$ and $\%$} \\
\hline 0 & 64 & 20 \\
\hline 1 & 177 & 55 \\
\hline 2 & 50 & 15 \\
\hline $3+$ & 32 & 10 \\
\hline \multicolumn{3}{|l|}{ Maternal characteristics } \\
\hline Age (years), mean and SD & $31 \cdot 8$ & $5 \cdot 4$ \\
\hline \multicolumn{3}{|l|}{ Educational level, $n$ and \% } \\
\hline$\leq \mathrm{GCSE}$ & 124 & 38 \\
\hline$>$ GCSE, < degree & 118 & 37 \\
\hline Degree or above & 82 & 25 \\
\hline \multicolumn{3}{|l|}{ Clothing size, $n$ and $\%$} \\
\hline$\leq$ UK size $16^{*}$ & 274 & 85 \\
\hline >UK size 16 & 50 & 15 \\
\hline \multicolumn{3}{|c|}{ Employed since the birth of their child, $n$ and \% } \\
\hline No & 138 & 43 \\
\hline Yes & 286 & 57 \\
\hline \multicolumn{3}{|c|}{ Maternal psychological factors, median and IQR } \\
\hline General control score & 27 & $25-29$ \\
\hline Well-being score & 13 & $9-17$ \\
\hline General self-efficacy score & 15 & $14-16$ \\
\hline Self-efficacy for healthy eating score & 15 & $14-15$ \\
\hline Food involvement score & 45 & $42-47$ \\
\hline \multicolumn{3}{|l|}{ Maternal feeding practices, mean and SD } \\
\hline Overt control score & 19 & 3.3 \\
\hline Covert control score & 13 & 5 \\
\hline \multicolumn{3}{|l|}{ Home and mealtime characteristics } \\
\hline \multicolumn{3}{|l|}{ Food security, $n$ and $\%$} \\
\hline Food secure & 268 & 83 \\
\hline Food insecure/hungry & 55 & 17 \\
\hline \multicolumn{3}{|c|}{ Child has eaten evening meals with the family, $n$ and $\%$} \\
\hline Never & 6 & 2 \\
\hline Monthly & 6 & 2 \\
\hline Weekly & 89 & 27 \\
\hline Daily & 223 & 69 \\
\hline \multicolumn{3}{|c|}{ Child has eaten meals with the television on, $n$ and $\%$} \\
\hline Never & 106 & 33 \\
\hline Monthly & 17 & 5 \\
\hline Weekly & 89 & 27 \\
\hline Daily & 112 & 35 \\
\hline \multicolumn{3}{|c|}{ Child has consumed takeaway foods, $n$ and $\%$} \\
\hline Never & 115 & 35 \\
\hline Monthly & 152 & 47 \\
\hline Weekly & 57 & 18 \\
\hline \multicolumn{3}{|l|}{ Child has eaten meals at a table, $n$ and $\%$} \\
\hline Never & 10 & 3 \\
\hline Weekly & 22 & 7 \\
\hline Daily & 292 & 90 \\
\hline \multicolumn{3}{|c|}{ Amount of time daily spent in front of a screen, $n$ and \% } \\
\hline$\leq 2 \mathrm{~h}$ & 195 & 60 \\
\hline$>2 \mathrm{~h}$ & 129 & 40 \\
\hline
\end{tabular}

IQR, interquartile range; GCSE, General Certificate of Secondary Education.

*UK size 16 is equivalent to European size 44 or American size 12. 
the variables food security and mealtime environment. Families in the present study came from a range of backgrounds; $38 \%$ of mothers had a low educational attainment (General Certificate of Secondary Education or lower) and $17 \%$ of the households were classed as food insecure/hungry. The majority ( $85 \%$ ) of mothers reported wearing clothes which were UK size 16 (European size 44, American size 12) or smaller.

\section{Cluster analysis}

The dendrogram resulting from the cluster analysis is shown in the online supplementary material, Supplemental Fig. 1; from this two distinct clusters were identified. Mothers in cluster 1 tended to have higher scores for all of the psychological variables compared with those in cluster 2 (all $P \leq 0 \cdot 001$, data not shown) showing that mothers in cluster 1 tend to have higher levels of selfefficacy, perceived control, well-being and food involvement. Figure 1 displays the percentage of mothers in each cluster with scores on the psychological assessments above the median. There are clear differences between mothers in each cluster. For example, $79 \%$ of mothers in cluster 1 had a well-being score above the median compared with only $7 \%$ of those in cluster 2 . Therefore cluster 1 was termed 'more resilient' and cluster 2 was termed 'less resilient'. Resilience is a psychological concept from personality theory and refers to a person's ability to respond and adapt effectively to challenges and adversity ${ }^{(28)}$.

Differences in maternal and home/mealtime characteristics according to mother's cluster membership were explored. Mothers who were in the less resilient cluster tended to be of lower educational attainment $(P \leq 0 \cdot 001)$ and to have more children $(P=0.03)$; in addition they were more likely to live in a food-insecure household $(P \leq 0 \cdot 001)$. In terms of how they shaped their children's eating environment, mothers in the less resilient cluster were less likely to use a covert style of feeding practice to control their children's diet $(P=0.002)$ and their children ate meals while sitting at a table less often $(P=0.03)$ and were more likely to consume takeaway foods $(P=0.05)$. Their children were also more likely to spend more hours in front of a screen $(P=0 \cdot 01)$.

\section{Association with child's quality of diet}

Children of mothers in the less resilient cluster tended to consume fewer weekly portions of fruit and vegetables, less water and more crisps, confectionery, white bread and low-calorie soft drinks (all differences $P \leq 0.05$ ) than children with mothers in the more resilient cluster.

A univariate analysis showed that children of mothers in the less resilient cluster tended to have a poorer-quality diet than those with mothers in the more resilient cluster. Being in the less resilient cluster was associated with a reduction in child's diet quality score of 0.61 SD (95\% CI $-0 \cdot 82,-0.40, P \leq 0 \cdot 001)$. The association between cluster membership and child's prudent diet score is displayed in Fig. 2. The association was attenuated but remained significant even after controlling for the maternal and mealtime environmental factors. The adjusted model is displayed in Table 3. This shows that, even after taking account of the effects of mealtime characteristics and maternal education, being a child of a mother in the less resilient cluster was associated with a reduction in diet quality score of 0.29 SD.

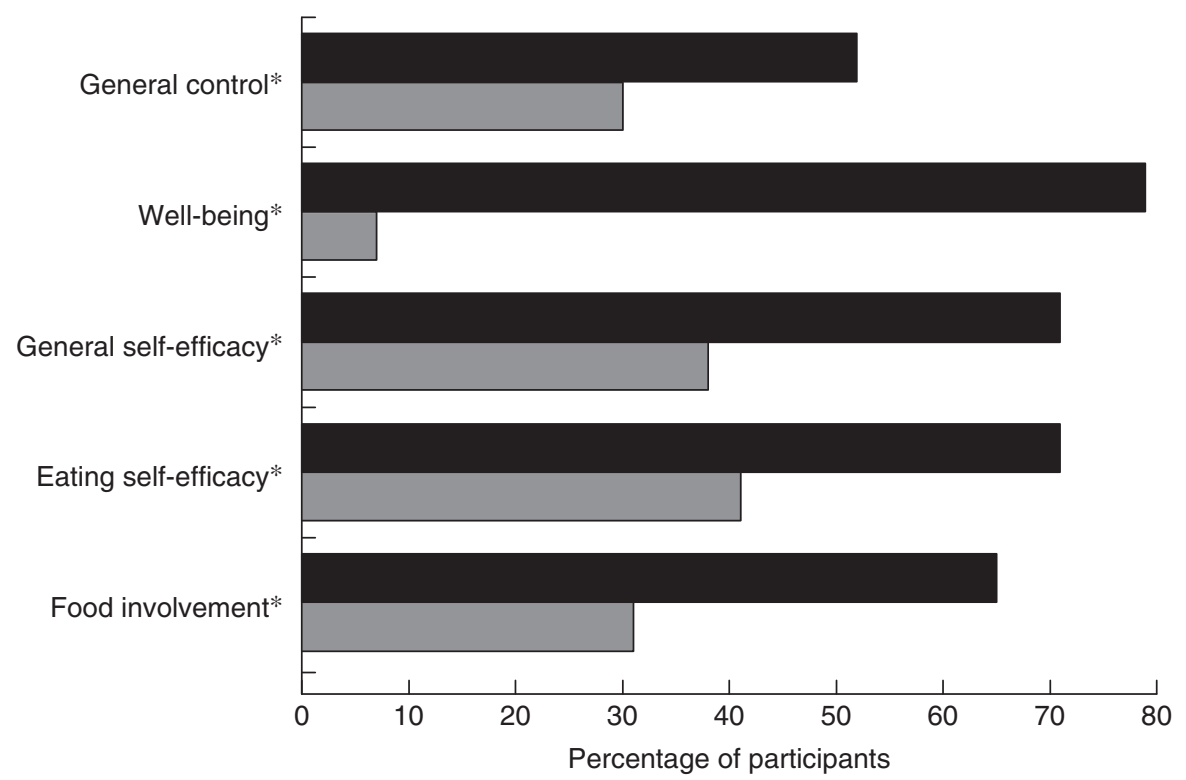

Fig. 1 The percentage of women with scores above the median for psychological factors according to cluster membership , cluster 1, 'more resilient'; $\square$, cluster 2, 'less resilient') among mothers of pre-school children ( $n$ 324) in the Southampton Initiative for Health, UK, December 2009-May 2010. *Difference in proportion is significant, $P \leq 0.001$ 


\section{Discussion}

The present study has demonstrated that mothers of preschool children cluster according to certain psychological characteristics. Mothers were classified into one of two clusters which were termed 'more resilient' and 'less resilient'. Those in the less resilient cluster felt less in control of their life, less able to overcome challenges both in general life and those specific to eating a healthy diet, had lower levels of well-being and did not give food a high priority. The reverse was true for those in the more resilient cluster. In addition, the cluster to which mothers belonged was associated with differences in mealtime environment and quality of their children's diets. Mothers in the less resilient cluster were less likely to use covert techniques to control their children's diet, such as limiting exposure to undesirable foods, and to encourage their children to eat meals while sitting at a table. Their children were also more likely to consume takeaway foods and spend more time in front of a screen. Importantly, our study demonstrated that children with mothers in the less

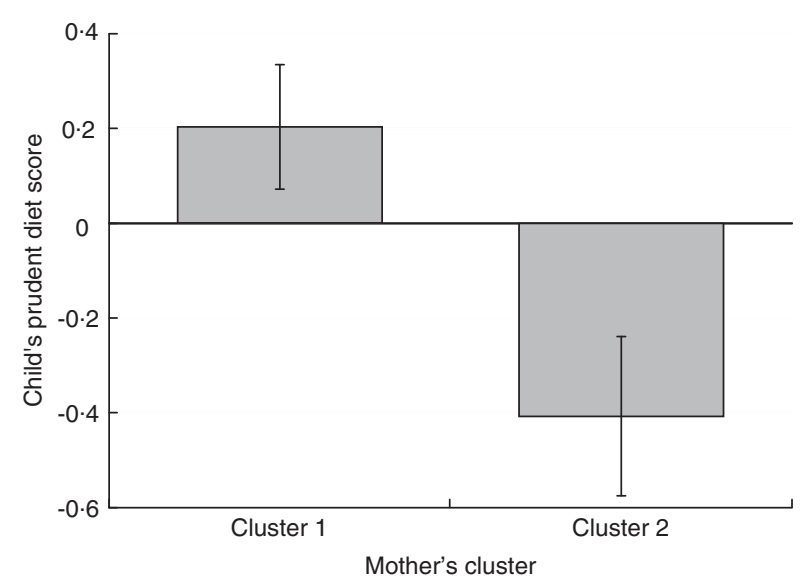

Fig. 2 Bar graph showing pre-school children's mean prudent diet score (Fisher-Yates Z-score) according to mothers' cluster membership (cluster 1, 'more resilient'; cluster 2, 'less resilient') among mother-child pairs ( $n$ 324) in the Southampton Initiative for Health, UK, December 2009-May 2010. Values are means with their $95 \%$ confidence intervals represented by vertical bars resilient cluster were more likely to have a poorer quality of diet and to consume more crisps, chocolate/sweets, white bread and low-calorie soft drinks as well as fewer vegetables, water and fruit.

A psychological perspective suggests that resilience is aligned with positive affect and long-term well-being and a coping disposition ${ }^{(29)}$. We speculate that self-efficacy and sense of control may be indicators of a coping disposition, based on the fact that people who are more resilient tend also to adopt a more positive profile of health behaviours and have better health outcomes ${ }^{(30)}$. Labelling the clusters of women as more or less resilient seemed to reflect the essential differences between them.

While, to our knowledge, the present study is the first to have grouped mothers in this way, it was unsurprising to find that the psychological factors were interrelated. Our previous work has demonstrated associations between levels of perceived control, self-efficacy and food involvement $^{(13)}$ and between food involvement and well-being ${ }^{(15)}$ in young women. In the present study, mothers in the less resilient cluster were more likely to have lower levels of education and to have more children at home. These findings are consistent with the literature which has shown that women with lower levels of education tended to have lower levels of control ${ }^{(31)}$, self-efficacy ${ }^{(32)}$, well-being and food involvement ${ }^{(15)}$.

Mothers in different clusters were also likely to manage their child's mealtime environment differently, which in turn was associated with children's diet quality. Our findings are consistent with those of other studies ${ }^{(22,33)}$. Those which have considered individual psychological factors have suggested that people with lower levels of well-being may be more likely to give up trying new behaviours if faced with conflict ${ }^{(33)}$. Therefore it is possible that mothers in the less resilient cluster felt less able to control their child's mealtime environment if, in the past, this has resulted in conflict with their children. Another study found that mothers who had higher levels of negative affect (low well-being) described feeling unable to control their children's diet ${ }^{(22)}$.

Although the association between cluster membership and quality of diet was independent of mealtime environment in the present study, the attenuation of effect size

Table 3 Mutually adjusted multivariate linear regression model showing the independent associations of cluster membership, maternal characteristics and mealtime environmental characteristics with pre-school children's prudent diet score among mother-child pairs $(n 324)$ in the Southampton Initiative for Health, UK, December 2009-May 2010

\begin{tabular}{|c|c|c|c|}
\hline Variable & Coefficient & $95 \% \mathrm{Cl}$ & $P$ value \\
\hline Mother's cluster membership & -0.29 & $-0.49,-0.08$ & 0.006 \\
\hline Mother's education (three categories) & 0.15 & $0.08,0.22$ & $<0.001$ \\
\hline Food insecurity (two categories) & -0.05 & $-0.11,0.01$ & 0.09 \\
\hline Covert control Z-score & $0 \cdot 19$ & $0.09,0.29$ & $<0.001$ \\
\hline Frequency of child sitting at a table to consume meals (four categories) & 0.20 & $0.09,0.32$ & $<0.001$ \\
\hline Frequency of child eating takeaway foods (four categories) & -0.15 & $-0.29,-0.02$ & 0.03 \\
\hline Child's average daily screen time $(\mathrm{h})$ & -0.08 & $-0.16,-0.003$ & 0.04 \\
\hline
\end{tabular}

Regression model is adjusted for all variables in the table as well as number of children and mother's age at interview. 
between cluster membership and child's quality of diet highlights the strong links between management of the mealtime environment and quality of diet in young children - an effect which has been described in other studies ${ }^{(7,34)}$. For example, mothers who use more covert control techniques to manage their child's food environment have been shown to have children who consume fewer unhealthy snacks and more fruits and vegetables ${ }^{(10)}$. In addition, eating meals while sitting at a table has consistently been demonstrated to have a positive effect on children's quality of diet ${ }^{(34)}$. Conversely, consumption of takeaway foods and time spent in front of a screen have been shown to have a negative influence on children's diets, with children who watch more television and consume more takeaway foods being more likely to consume unhealthy snack foods and sugar-sweetened beverages and less likely to consume fruit and vegetables ${ }^{(7,25,35)}$.

The independent contributions of the psychological cluster into which mothers were grouped (Table 3) suggested that cluster membership was an important influence on child's quality of diet. A key finding of our study is that the relationship between maternal resilience and child's diet was not completely explained by the way she controlled her child's mealtime environment. This highlights the importance of maternal psychological factors as an influence on pre-school children's quality of diet.

\section{Strengths and limitations}

To our knowledge, the present study is the first to have considered the interplay of mother's general self-efficacy, self-efficacy for healthy eating, perceived control, wellbeing and food involvement, and their role in determining the quality of pre-school children's diets. As our data are cross-sectional we cannot make inferences about cause and effect. In addition, our assessment of mother's clothing size as a proxy for BMI was a limitation as it did not account for mother's height, although in a large study of women clothing size was found to be similarly associated with chronic disease risk ${ }^{(26)}$. A strength of the study was the use of validated assessment methods and the use of trained interviewers who adhered to set protocols. The information was obtained by interview, rather than using self-completed questionnaires, thus reducing the possibility of misinterpretation of the questions and missing data. Dietary assessment in young children is challenging ${ }^{(36)}$ and relies on dietary information provided by a caregiver, which is likely to increase reporting error. Although FFQ may be prone to measurement error, they have been shown to be effective at ranking children according to their dietary patterns ${ }^{(36)}$ and the prudent dietary pattern was shown to be described accurately using the short FFQ designed for the present study. It is unlikely that measurement error in the assessment of diet would explain the findings presented here and indeed measurement error usually, but not always, reduces associations rather than amplifies them ${ }^{(37)}$. Participants were drawn from Sure Start Children's Centres which tend to operate in more disadvantaged areas in the towns and cities they serve. The mothers represented a wide range of educational attainment and other characteristics. We therefore would expect these findings to be of relevance beyond Southampton.

\section{Implications}

Our findings have implications for the design of future interventions to improve the diets of pre-school children and their families. Although there is a clear association between children's mealtime environment and their quality of diet, mothers who do not feel in control of life, are unable to overcome challenges and barriers to healthy eating, have lower levels of well-being and consider food to be a low priority are additionally likely to have children with poorer-quality diets. Therefore interventions designed to empower and support mothers may have additional benefit compared with giving advice on diet and mealtime management alone. Unless mothers feel able to act on this advice in their homes, their children's diets are unlikely to improve. This conclusion was also reached by a recent review of parent-focused interventions in children with non-clinical feeding problems, which suggested that parents need to be supported and empowered as well as educated to overcome the challenges in feeding young children ${ }^{(38)}$.

\section{Conclusion}

The present study has demonstrated the importance of both the environment in which pre-school children consume food as well as psychological characteristics of their mothers in predicting the diets of pre-school children. These findings suggest that multifaceted interventions are needed to improve childhood diet. Empowering mothers to feel more in control, more able to overcome barriers to feeding their children a healthy diet and to raise the priority mothers give to food is likely to benefit the quality of pre-school children's diets. These cross-sectional relationships require further exploration in prospective observational and intervention studies.

\section{Acknowledgements}

Acknowledgments: The authors thank the Sure Start Children's Centres and the mothers and children for giving their time. They are grateful to Vanessa Cox and the MRC LEU computing team for their invaluable help with the data, and to all working on the Southampton Initiative for Health (SIH). Financial support: This study was supported by the Medical Research Council (MRC) and the National Institute for Health Research (NIHR) Nutrition Biomedical Research Centre, University of Southampton. The MRC 
and the NIHR Nutrition Biomedical Research Centre had no role in the design, analysis or writing of this article. Conflict of interest: None. Authorship: M.J. coordinated the surveys and wrote the manuscript. H.M.I. and G.N. carried out the statistical analysis. M.E.B. and S.M.R. supervised M.J. and assisted in drafting the manuscript. M.E.B., J.B. and C.C. are the joint leads for the SIH. All authors reviewed drafts of the manuscript. Ethics of human subject participation: Ethical approval was granted by the University of Southampton School of Medicine ethics committee.

\section{Supplementary material}

To view supplementary material for this article, please visit http://dx.doi.org/10.1017/S136898001400250X

\section{References}

1. Fisk CM, Crozier SR, Inskip HM et al. (2011) Influences on the quality of young children's diets: the importance of maternal food choices. Br J Nutr 105, 287-296.

2. North K \& Emmett P (2000) Multivariate analysis of diet among three-year-old children and associations with sociodemographic characteristics. The Avon Longitudinal Study of Pregnancy and Childhood (ALSPAC) Study Team. Eur J Clin Nutr 54, 73-80.

3. Vereecken CA, Keukelier E \& Maes L (2004) Influence of mother's educational level on food parenting practices and food habits of young children. Appetite 43, 93-103.

4. Kranz S \& Siega-Riz AM (2002) Sociodemographic determinants of added sugar intake in preschoolers 2 to 5 years old. J Pediatr 140, 667-672.

5. Rosenkranz RR \& Dzewaltowski DA (2008) Model of the home food environment pertaining to childhood obesity. Nutr Rev 66, 123-140.

6. Wyse R, Campbell E, Nathan N et al. (2011) Associations between characteristics of the home food environment and fruit and vegetable intake in preschool children: a crosssectional study. BMC Public Health 11, 938.

7. Campbell KJ, Crawford DA \& Ball K (2006) Family food environment and dietary behaviors likely to promote fatness in 5-6 year-old children. Int J Obes (Lond) 30, 1272-1280.

8. Pilgrim A, Barker M, Jackson A et al. (2012) Does living in a food insecure household impact on the diets and body composition of young children? Findings from the Southampton Women's Survey. J Epidemiol Community Health 66, e6.

9. Fitzpatrick E, Edmunds LS \& Dennison BA (2007) Positive effects of family dinner are undone by television viewing. $J$ Am Diet Assoc 107, 666-671.

10. Brown KA, Ogden J, Vogele C et al. (2008) The role of parental control practices in explaining children's diet and BMI. Appetite 50, 252-259.

11. Spurrier NJ, Magarey AA, Golley R et al. (2008) Relationships between the home environment and physical activity and dietary patterns of preschool children: a crosssectional study. Int J Behav Nutr Phys Act 5, 31.

12. Rodenburg G, Oenema A, Kremers SP et al. (2013) Clustering of diet- and activity-related parenting practices: crosssectional findings of the INPACT study. Int J Behav Nutr Phys Act 10, 36.

13. Lawrence W, Schlotz W, Crozier S et al. (2011) Specific psychological variables predict quality of diet in women of lower, but not higher, educational attainment. Appetite 56, 46-52.

14. Barker M, Lawrence W, Woadden J et al. (2008) Women of lower educational attainment have lower food involvement and eat less fruit and vegetables. Appetite 50, 464-468.
15. Jarman M, Lawrence W, Ntani G et al. (2012) Low levels of food involvement and negative affect reduce the quality of diet in women of lower educational attainment. J Hum Nutr Diet 25, 444-452.

16. Cooke LJ, Wardle J, Gibson EL et al. (2004) Demographic, familial and trait predictors of fruit and vegetable consumption by pre-school children. Public Health Nutr 7, 295-302.

17. McGowan L, Croker H, Wardle J et al. (2012) Environmental and individual determinants of core and non-core food and drink intake in preschool-aged children in the United Kingdom. Eur J Clin Nutr 66, 322-328.

18. Fisher JO, Mitchell DC, Smiciklas-Wright $\mathrm{H}$ et al. (2002) Parental influences on young girls' fruit and vegetable, micronutrient, and fat intakes. J Am Diet Assoc 102, 58-64.

19. Ajzen I (2002) Perceived behavioural control, self-efficacy, locus of control, and the theory of planned behavior. J Appl Soc Psychol 32, 665-683.

20. Bandura A (1997) Self-Efficacy, The Exercise of Control, 10th ed. New York: W.H. Freeman and Co.

21. Ohly H, Pealing J, Hayter AK et al. (2013) Parental food involvement predicts parent and child intakes of fruits and vegetables. Appetite 69, 8-14.

22. Ystrom E, Barker M \& Vollrath ME (2012) Impact of mothers' negative affectivity, parental locus of control and childfeeding practices on dietary patterns of 3-year-old children: the MoBa Cohort Study. Matern Child Nutr 8, 103-114.

23. Barker M, Baird J, Lawrence W et al. (2011) The Southampton Initiative for Health: a complex intervention to improve the diets and increase the physical activity levels of women from disadvantaged communities. J Health Psychol 16, 178-191.

24. Crozier SR, Inskip HM, Barker ME et al. (2009) Development of a 20-item food frequency questionnaire to assess a 'prudent' dietary pattern among young women in Southampton. Eur J Clin Nutr 64, 99-104.

25. MacFarlane A, Cleland V, Crawford D et al. (2009) Longitudinal examination of the family food environment and weight status among children. Int J Pediatr Obes $\mathbf{4}$, 343-352.

26. Han TS, Gates E, Truscott E et al. (2005) Clothing size as an indicator of adiposity, ischaemic heart disease and cardiovascular risks. J Hum Nutr Diet 18, 423-430.

27. Milligan GM \& Cooper MC (1987) Methodology review: clustering methods. Appl Psychol Meas 11, 329-354.

28. Block J \& Kremen AM (1996) IQ and ego-resiliency: conceptual and empirical connections and separateness. J Pers Soc Psychol 70, 349-361.

29. Ong AD, Bergeman CS, Bisconti TL et al. (2006) Psychological resilience, positive emotions, and successful adaptation to stress in later life. J Pers Soc Psychol 91, 730-749.

30. Steptoe A, Dockray S \& Wardle J (2009) Positive affect and psychobiological processes relevant to health. J Pers 77, 1747-1776.

31. Barker M, Lawrence W, Crozier S et al. (2009) Educational attainment, perceived control and the quality of women's diets. Appetite 52, 631-636.

32. Leganger A \& Kraft P (2003) Control constructs: do they mediate the relation between educational attainment and health behaviour? J Health Psychol 8, 361-372.

33. Vollrath ME, Torgersen S \& Alnaes R (1998) Neuroticism, coping and chang in MCMI-II clinical syndromes: test of a mediator model. Scand J Psychol 39, 15-24.

34. Rockett HRH (2007) Family dinner: more than just a meal. J Am Diet Assoc 107, 1498-1501.

35. Miller SA, Taveras EM, Rifas-Shiman SL et al. (2008) Association between television viewing and poor diet quality in young children. Int J Pediatr Obes 3, 168-176.

36. Jarman M, Fisk CM, Ntani G et al. (2014) Assessing diets of 3-year-old children: evaluation of an FFQ. Public Health Nutr 17, 1069-1077. 
37. Jurek AM, Greenland S, Maldonado G et al. (2005) Proper interpretation of non-differential misclassification effects: expectations vs observations. Int J Epidemiol 34, 680-687.

38. Mitchell GL, Farrow C, Haycraft E et al. (2013) Parental influences on children's eating behaviour and characteristics of successful parent-focussed interventions. Appetite 60, 85-94.

39. Schwarzer R \& Jerusalem M (1995) The General Self-Efficacy Scale, vol. 2, pp. 1-21. Berlin: Freie University; available at http://userpage.fu-berlin.de/ health/engscal.htm

40. Schwarzer R \& Renner B (1998) Health Specific Self-Efficacy Scales, vol. 1, pp. 1-7. Berlin: Freie University; available at http://userpage.fu-berlin.de/ health/healself.pdf

41. Bobak M, Pikhart H, Rose R et al. (2000) Socioeconomic factors, material inequalities, and perceived control in self-rated health: cross-sectional data from seven postcommunist countries. Soc Sci Med 51, 1343-1350.

42. Bell R \& Marshall DW (2003) The construct of food involvement in behavioral research: scale development and validation. Appetite 40, 235-244.

43. World Health Organization (1998) Well-Being Measures in Primary Health Care/The DepCare Project. Report of a WHO Meeting, Stockholm, Sweden, 12-13 February 1998. Copenhagen: WHO Regional Office for Europe.

44. Ogden J, Reynolds R \& Smith A (2006) Expanding the concept of parental control: a role for overt and covert control in children's snacking behaviour? Appetite 47, 100-106.

45. Blumberg SJ, Bialostosky K, Hamilton WL et al. (1999) The effectiveness of a short form of the Household Food Security Scale. Am J Public Health 89, 1231-1234. 